\title{
Immune-Complex Infectious Bursal Disease Virus versus Live Attenuated Vaccines to Protect SPF Chicken against Very Virulent Virus Challenge
}

\author{
Moustafa S. Abou El-Fetouh, Magdy H. Hafez, El-Sayed R. El-Attar, and Mohammed Ezzat El-Agamy* \\ Department of Pathology, Faculty of Veterinary Medicine, Zagazig University, Egypt \\ ${ }^{*}$ Corresponding author's Email: aboelagamy2005@yahoo.co.uk; ORCID: 0000-0003-2416-2947
}

Received: 24 Sept. 2020

Accepted: 05 Nov. 2020

\begin{abstract}
In this study infectious bursal disease (IBD) vaccinations were evaluated against very virulent IBD (vvIBDV) challenge and were compared. A total of 120-day-old white Leghorn SPF chickens were divided into 6 groups (each was 20 birds). Two groups were vaccinated on either day 1 with an immune-complex vaccine. The second groups were vaccinated at days 9 and 14 of age using intermediate and intermediate plus IBD vaccines, respectively the balance groups are controls. All vaccines were administered according to the manufacturer's instructions. The challenge was conducted on the 16 days of age using $10^{5} \mathrm{EID}_{50} / 0.1 \mathrm{ml}$ of a vvIBDV strain via the oculonasal route. The antibody immune response was monitored in all groups at 14,21, 28, and 35 days of age. The performance, bursal gross lesions, challenge virus detection, and bursal histopathology were evaluated in vaccinated non challenged and vaccinated challenged birds at days 21 and 28 of age. All vaccinated groups were protected against the vvIBDV challenge compared to $40 \%$ mortality in the challenge control group. Both the immune-complex and live attenuated IBD vaccine groups showed similar bursa body weight (BB) ratios compared to the negative control group. The immune-complex vaccinated groups antibody titers were significantly higher except on 28th day of age. Upon challenge, the intermediate/intermediate plus vaccinated challenged group showed higher antibody titers at 21 and $35^{\text {th }}$ with the challenge virus detection and quantification on day 28 . The immune-complex vaccinated challenged group developed milder bursal histopathology signs but no differences between the 2 vaccine programs were seen. It can be understandable, the use of either immune-complex vaccine at day-old or early vaccination with intermediate followed by intermediate plus live attenuated IBD vaccines induced protective antibody titers and protect chickens against an early vvIBDV challenge. The suggested schedules need further evaluation in commercial broilers with maternal derived IBD antibodies to simulate field conditions.
\end{abstract}

Keywords: Immune-Complex vccine, Infectious Bursal Disease, Live Attenuated Vaccine, SPF Chicken

\section{INTRODUCTION}

Infectious Bursal Disease (IBD) is an acute and highly contagious disease in chickens at 3 weeks of age and older causing high mortality and immunosuppression leading to a variety of secondary infections and a decreased response to vaccinations (Eterradossi and Saif, 2020). IBDV belongs to the Birnaviridae family within the genus Avibirnavirus (Delmas et al., 2019). The virus is nonenveloped, single shelled with a diameter of 60 to $70 \mathrm{~nm}$ (Alkie and Rautenschlein, 2016).

IBDV has a predilection for the immature actively dividing B lymphocytes and causes lytic infection of IgM bearing $\mathrm{B}$ cells resulting in the decrease in circulating $\mathrm{IgM}^{+}$cells (Sivanandan and Maheswaran, 1980; Dey et al.,
2019). Infected chicken produces less level of antibodies against the antigen (Ingraoet al., 2013). IBDV induced humoral deficiency is reversible and overlaps with the restoring of bursal morphology (Sharmaet al., 2000).

Three main clinical symptoms of the disease were reported and include the classical form caused by the classic moderate virulent strains of IBDV and manifested by acute depression followed by typical signs and lesions with $10-50 \%$ mortality. The acute form is caused by very virulent strains of IBDV (vvIBDV) characterized by acute progressive and typical clinical signs resulting in high mortality rates on affected farms (50-100\%) (Stoute et al., 2009; Ewies et al., 2017; Eterradossi and Saif, 2020). Finally, the immunosuppressive form, principally described in the United States, is caused by low- 
pathogenicity strains of IBDV and variant strains (e.g. Delaware strains) with few clinical signs, no mortality but with marked bursal lesions and concurrent infections with other agents (Dey et al., 2019; Shehata et al., 2019).

The available live vaccines against IBDV are categorized as "mild", "intermediate" and "hot" according to their degree of virulence (Rautenschleinet al., 2003). Killed virus vaccines in oil-adjuvant can prolong the duration of immunity in breeder flocks in addition to containing both standard and variant IBDV strains. Therefore, maternal antibody profiling of the breeder flock should be done to assess the effectiveness of vaccination and the persistence of antibody (Eterradossi and Saif, 2020). Mild vaccines are not very effective in the presence of high levels of maternal antibodies or against very virulent strains of IBDV. Intermediate and hot vaccines are much more effective but may induce moderate to severe lesions in the bursa of Fabricius (BF) (Camilotti et al., 2016).

To overcome the problem of maternal immunity interference, the IBDV vectored vaccines were developed. For instance, herpesviruses expressing the surface viral protein 2 (VP2) of IBDV (Perozo et al., 2009) and immune complex vaccines containing an IBDV-specific antibody and live-attenuated IBDV (Schat et al., 2011). Both types are commercially available and administered in-ovo or at one-day of age without maternal immunity interference (Muller et al., 2012).

In this study, the administration of immune-complex IBD vaccine (Bursaplex ${ }^{\circledR}$ ) at day-old was compared with the use of an intermediate followed by an intermediate plus vaccines at 9 and 14 day-old, respectively, in SPF chickens. The comparison items included the clinical protection, bursal pathology, serology as well as detection and quantification of the challenge virus.

\section{MATERIALS AND METHODS}

\section{Ethical approval}

All experimental procedures were reviewed and approved by the Faculty of Veterinary Medicine, Zagazig University, Egypt (FVM/ZAG-191207).

\section{Vaccines and viruses}

Bursaplex® (Zoetis, USA) is an immune-complex IBD vaccine that contains an embryo origin IBD live strain in conjunction with bursal disease antiserum and recommended for subcutaneous injection of chickens at one day of age. Bursine ${ }^{\circledR}-2$ "intermediate live attenuated IBD vaccine" and Bursine plus ${ }^{\circledR}$ "intermediate Plus live attenuated IBD vaccine" (Zoetis, Belgium) were used. The challenge vvIBDV strain BSU-03-2016 (acc.no. KX077978) was retrieved from the repository of the Poultry Diseases Department, Faculty of Veterinary Medicine, Beni-Suef University, Egypt. The virus was propagated and titrated in 11 day-old SPF embryonated chicken eggs (Eterradossi and Saif, 2016).

\section{Experimental design}

A total of 120-day-old white Leghorn SPF chickens were divided into 6 groups ( 20 birds) placed in a negative pressure chicken isolator. Birds were vaccinated on either day 1 or days 9and 14 of age according to the experimental design summarized in table 1 . All vaccines were administered according to the manufacturer's instructions. The challenge was conducted on the $16^{\text {th }}$ day of age using $10^{5} \mathrm{EID}_{50} / 0.1 \mathrm{ml}$ of the vvIBDV strain via the oculonasal route (Eterradossi and Saif, 2016).

\section{IBDV ELISA testing}

Collected chicken sera were checked for IBD specific antibodies using ID Screen ${ }^{\circledR}$ IBD Indirect ELISA kit (IDvet, France) according to manufacturer instructions.

\section{IBDV RT-PCR detection}

Vaccinal and vvIBDV detection and quantification in 5 pooled bursal homogenates collected at the $28^{\text {th }}$ day of age were conducted using qualitative Kylt ${ }^{\circledR}$ IBDV Pathotyping kits (AniCon Labor GmbH, Germany). The RNA was extracted using Kylt ${ }^{\circledR}$ RNA/DNA Purification kit (AniCon Labor $\mathrm{GmbH}$, Germany) according to the manufacturer's instructions. The reaction performed in a $20 \mu 1$ volume consisted of $10 \mu \mathrm{l}$ of $2 \mathrm{x}$ RT-qPCR-Mix, $6 \mu \mathrm{l}$ of Detection-Mix, and $4.0 \mu \mathrm{l}$ of the tested RNA samples. The Kylt@ kit thermal Profile III was; reverse transcription at $50{ }^{\circ} \mathrm{C}$ for $10 \mathrm{~min}$, activation of Polymerase at $95{ }^{\circ} \mathrm{C}$ for $1 \mathrm{~min}$, and 42 cycles of Denaturation at $95{ }^{\circ} \mathrm{C}$ for $10 \mathrm{sec}$, annealing and extension at $55^{\circ} \mathrm{C}$ for $1 \mathrm{~min}$. The fluorescence detection channels were fluorescein (FAM) for vvIBDV, Cy5 for vaccinal IBDV, and HexachloroFluorescein (HEX) for the internal kit control.

\section{Histopathology}

The bursa of Fabricius, thymus, spleen, and kidneys were collected from 5 chickens at 21 and 28th days of age. The formalin-fixed paraffin-embedded specimens were sectioned $(4-5 \mu \mathrm{m})$ and stained with hematoxylin and 
eosin stain and examined microscopically (Suvarna et al., 2018).

\section{Statistical analysis}

The differences in body weights, bursal body weight antibody titers were estimated using one-way ANOVA with multiple comparison Tukey's post-test through GraphPad Prism version 5.00 for Windows (GraphPad Software, San Diego California USA, www.graphpad.com). ratios (bursal weight/bodyweight $\times 1000$ ), and ELISA

Table 1. Experimental design of different vaccination schedules, sampling, and sample testing

\begin{tabular}{|c|c|c|c|}
\hline Groups & Vaccination & $\begin{array}{l}\text { Challenge } \\
\text { at } 16^{\text {th }} \text { day }\end{array}$ & Monitoring, sampling, and measurements \\
\hline Control negative & - & - & \multirow{6}{*}{$\begin{array}{l}\text { - ELISA: IBD ELISA at } 0 \text { day } \\
\text { - Daily monitoring for clinical signs and mortality } \\
\text { - } \text { At } 14,28,35^{\text {th }} \text { day } \\
\text { - Serology (IBD ELISA) } \\
\text { - On } 21,28^{\text {Th }} \text { day: } \\
\text { - Body weights, and Bursa/body weight ratio } \\
\text { - Histopathology } \\
\text { - IBD PCR }\end{array}$} \\
\hline Bursaplex & $1^{\text {st }}$ day: Bursaplex & - & \\
\hline $\begin{array}{l}\text { Interm./Interm. } \\
\text { plus }\end{array}$ & $\begin{array}{l}9^{\text {th }}: \text { intermediate IBD vaccine } \\
14^{\text {th }} \text { day: intermediate plus } \\
\text { IBD vaccine }\end{array}$ & - & \\
\hline Bursaplex- $\mathrm{CH}$ & $1^{\text {st }}$ day: Bursaplex & + & \\
\hline $\begin{array}{l}\text { Interm./Interm. } \\
\text { Plus-CH }\end{array}$ & $\begin{array}{l}9^{\text {th }}: \text { intermediate IBD vaccine } \\
14^{\text {th }} \text { day: intermediate plus } \\
\text { IBD vaccine }\end{array}$ & + & \\
\hline Challenge control & - & + & \\
\hline
\end{tabular}

${ }^{1}$ Challenge was conducted on the $16^{\text {th }}$ day of age using $10^{5} \mathrm{EID}_{50} / 0.1 \mathrm{ml}$ of the vvIBDV strain via the oculonasal route

\section{RESULTS}

\section{Clinical protection of immune-complex and live attenuated IBD vaccines}

All vaccinated groups were protected against the vvIBDV challenge. Meanwhile, birds in the challenge control group showed $40 \%$ mortalities between day 4 and 5 post-challenge (Table 2). Upon necropsy, the challenge control group showed typical IBD lesions including hemorrhage on the thigh and breast muscle as well as bursal inflammation and enlargement. In vaccinated groups, mild bursal enlargement was noticed. no significant differences in body weights though lower body weights were observed in all groups compared to the negative control group (Table 2).

\section{Bursa body weight ratio}

Bursal body weight ratios (BB ratios) were more indicative of the clinical protection afforded by different vaccines. Both Bursaplex and intermediate/intermediate plus vaccinated non challenged groups showed higher $B B$ ratios compared to the negative control group. The $\mathrm{BB}$ ratios were always significantly lower than the challenge control group especially in the Bursaplex vaccinated challenged group at 28 days of age (Figure 1).

\section{IBDV serology in vaccinated and vaccinated challenged groups}

As shown in figure 2, the ELISA antibody titers in the vaccinated nonchallenged groups were relatively higher in Bursaplex vaccinated groups at 14 and 21 dayold compared to the intermediate/intermediate plus vaccinated group. However, both groups showed no differences at 28 days of age, but the antibody titers decay was faster in the intermediate/intermediate plus vaccinated group at day 35 (figure 2A). No significant differences between the vaccination regimes upon challenge, however, the intermediate/intermediate plus vaccinated groups showed relatively higher titers (figure $2 \mathrm{~B}$ ).

\section{Challenge virus detection and quantification}

The challenge virus detection and quantification on the $28^{\text {th }}$ day of age are shown in table 3 . The vvIBDV was evident in the intermediate/intermediate plus vaccinated group however, no challenge virus detection was observed in the Bursaplex vaccinated challenged group. The virus was confirmed to be vvIBDV by partial sequencing of the VP2 gene (data not shown)

\section{Histopathology}

At 21 days of age, no significant bursal changes were observed in Bursaplex or Intermediate/intermediate plus vaccinated non-challenged groups except for slight B-cell proliferation of the cortical medullary cells with normal mucosal folds of the bursa in the Intermediate/intermediate plus vaccinated non-challenged group (figure 3C). Similarly, upon challenge no prominent changes while the 
Bursaplex vaccinated challenged group showed lymphoproliferative follicular tissue with highly activated cortical lymphocytes (figure 3D). The challenge control showed massive degenerative changes, central necrosis and apoptosis, inflammatory cell infiltration, and aggregations of necrotic and apoptotic (Figure 3F).

By the $28^{\text {th }}$ day of age, similar bursal appearance in the vaccinated non challenged groups were observed (Figure $4 \mathrm{~B}$ and $\mathrm{C}$ ). In the vaccinated challenged groups, the Bursaplex vaccinated group showed a well-formed healthy epithelial lining of the pica and characteristic lymphoproliferative follicular tissue, and the cortical lymphocytes were highly activated and appeared with compacted deep basophilic nuclei and scanty cytoplasm (Figure 4D). The Bursa of intermediate/intermediate plus vaccinated challenged chickens' group is showed multiple immune-reactive lymphoid follicles and mild thickening of the interstitial connective tissue by fibroblastic proliferation (Figure 4E). The challenge control group bursae showed medullary massive central necrosis, apoptosis, and sometimes heterophilic infiltration. The cortical layer appeared completely necrotic with the disappearance of almost all the lymphoid cells (Figure 4F).

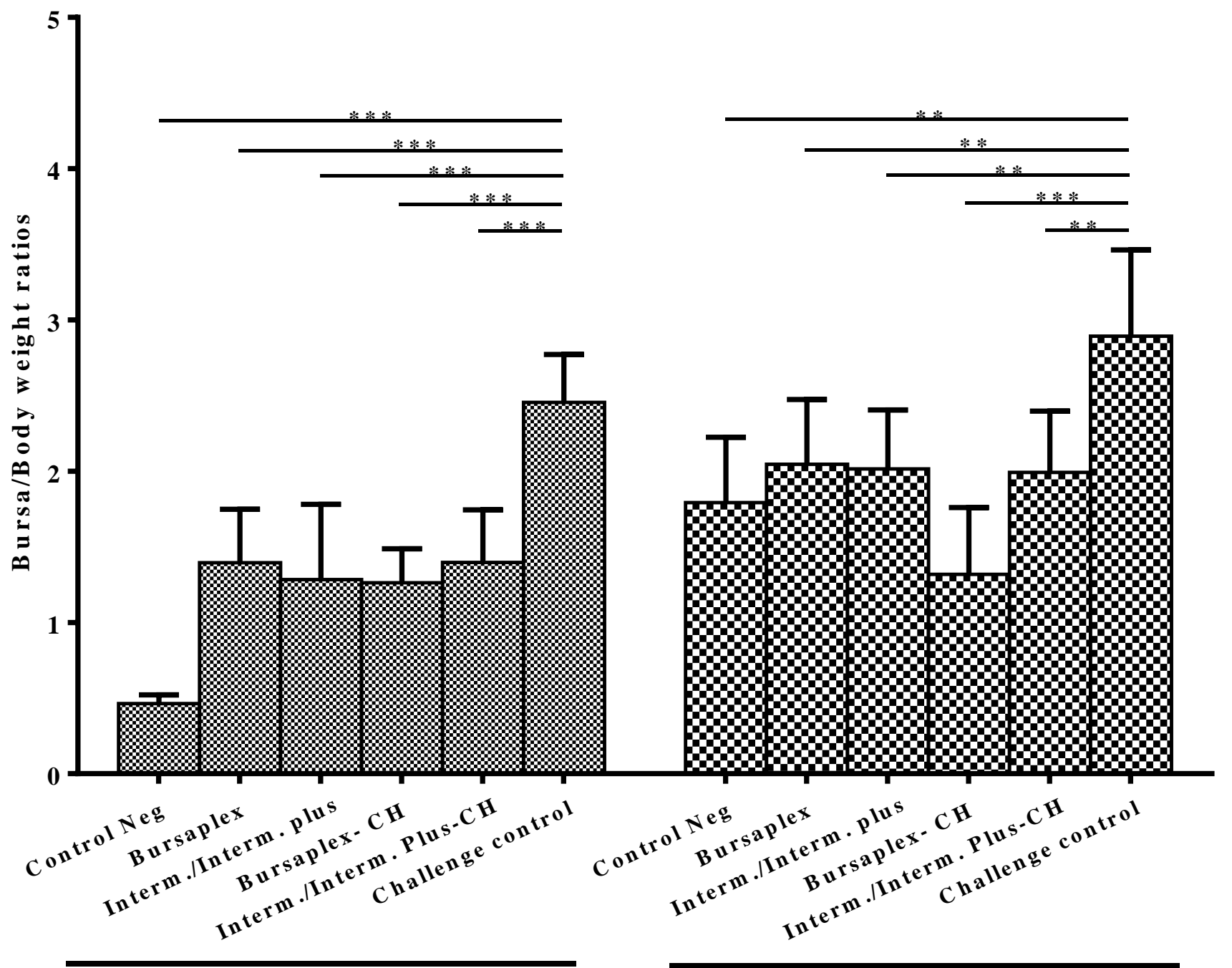

21 d a y - old

28 d a y - o ld

Figure 1. Bursa body weight ratios in different experimental groups at 21 and 28 day-old. The stars indicate significant differences at $* \leq 0.05, * * \leq 0.001, * * * \leq 0.0001$ 
A

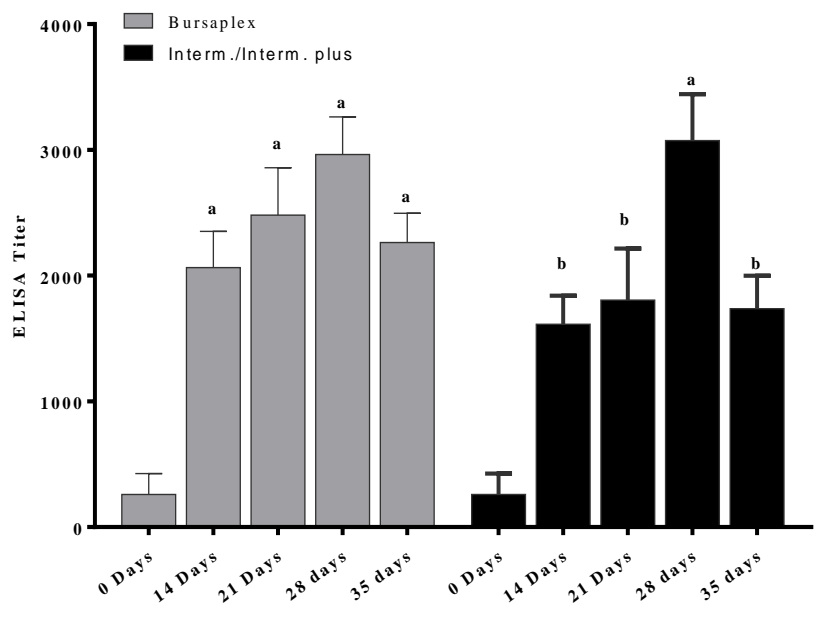

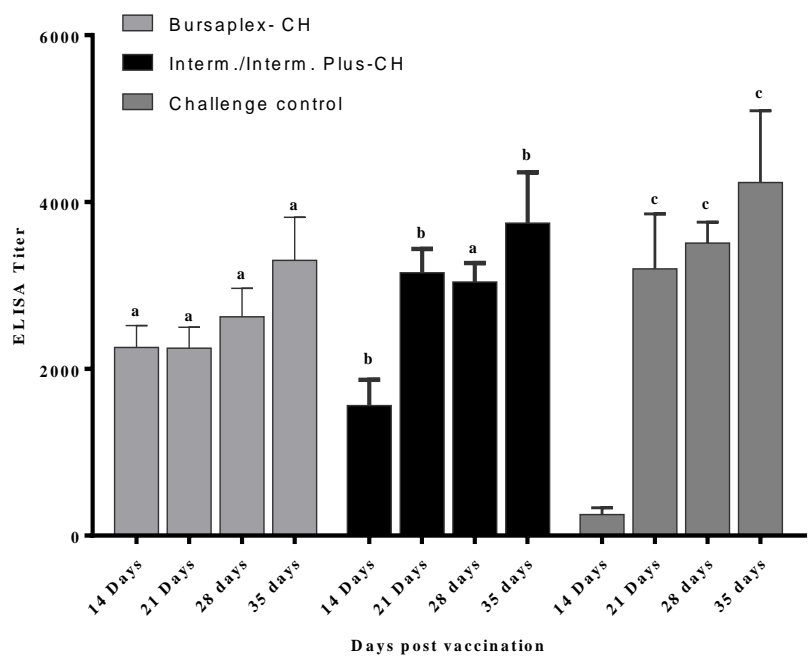

Figure 2. ELISA antibody titers in vaccinated non challenged (A) and vaccinated challenged groups (B) at 14, 21, 28, and 35 day-old. Bars with different small letters at the same time point are significantly different $(\mathrm{p} \leq 0.05)$

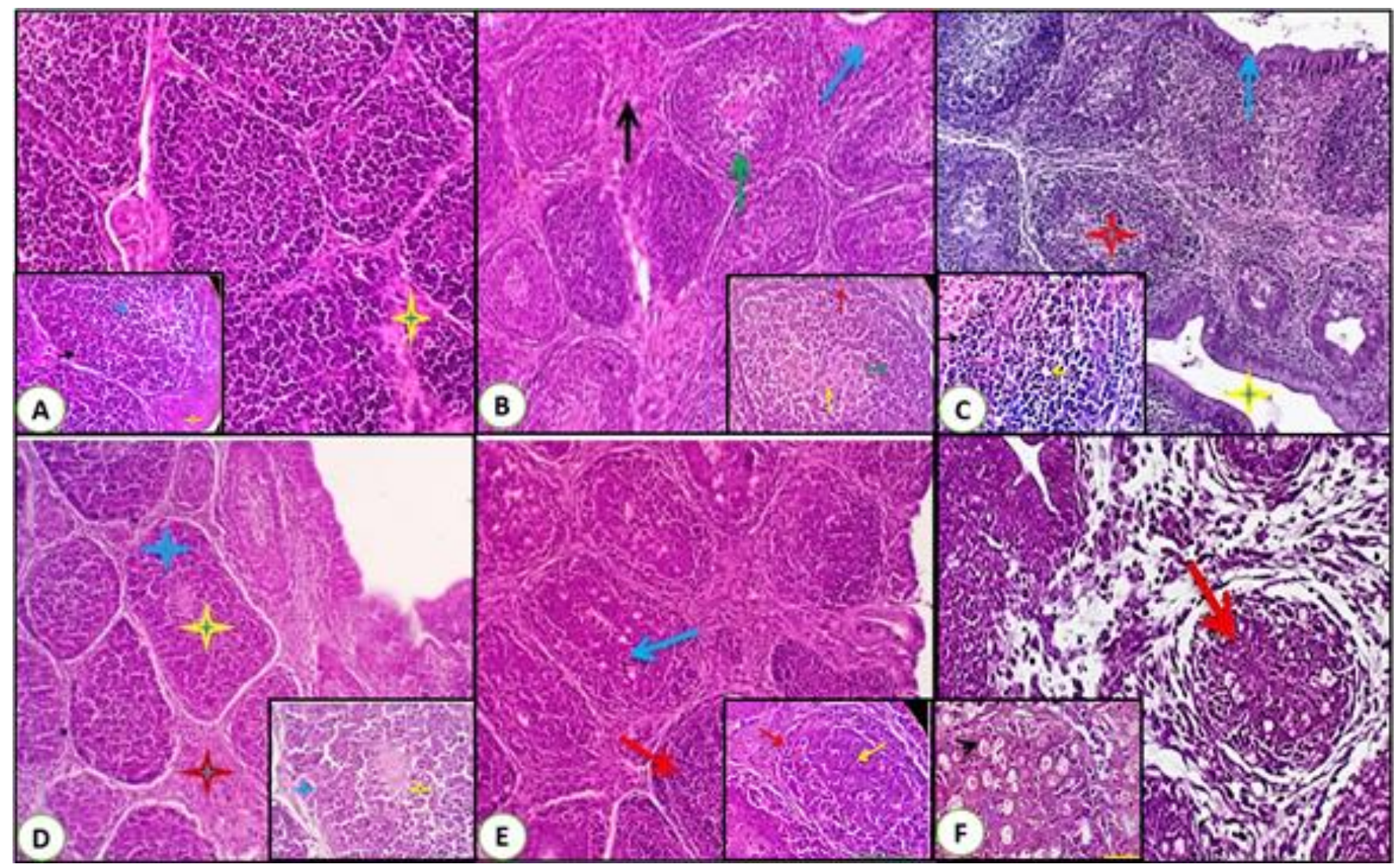

Figure 3. Bursa histopathology in different groups of chickens at 21 day-old. A, B: Normal bursal histology in negative control and Bursaplex vaccinated non-challenged group. C: Intermediate/intermediate plus vaccinated non challenged group showing slight B-cell proliferation of the cortical medullary cells (red and yellow arrow) with normal mucosal folds of the bursa (blue arrow). D: Bursaplex vaccinated challenged group showing lymphoproliferative follicular tissue with prominent central medullary lymphocytes (yellow stars) and the cortical lymphocytes were highly activated (dark blue stars). E: Intermediate/intermediate plus vaccinated challenged group showing normal bursal folds and immune-reactive lymphoid follicles. F: Challenge control showing degenerative changes (red arrows), massive central necrosis and apoptosis, inflammatory cells infiltration with the presence of aggregates of necrotic and apoptotic debris (black arrowhead). 


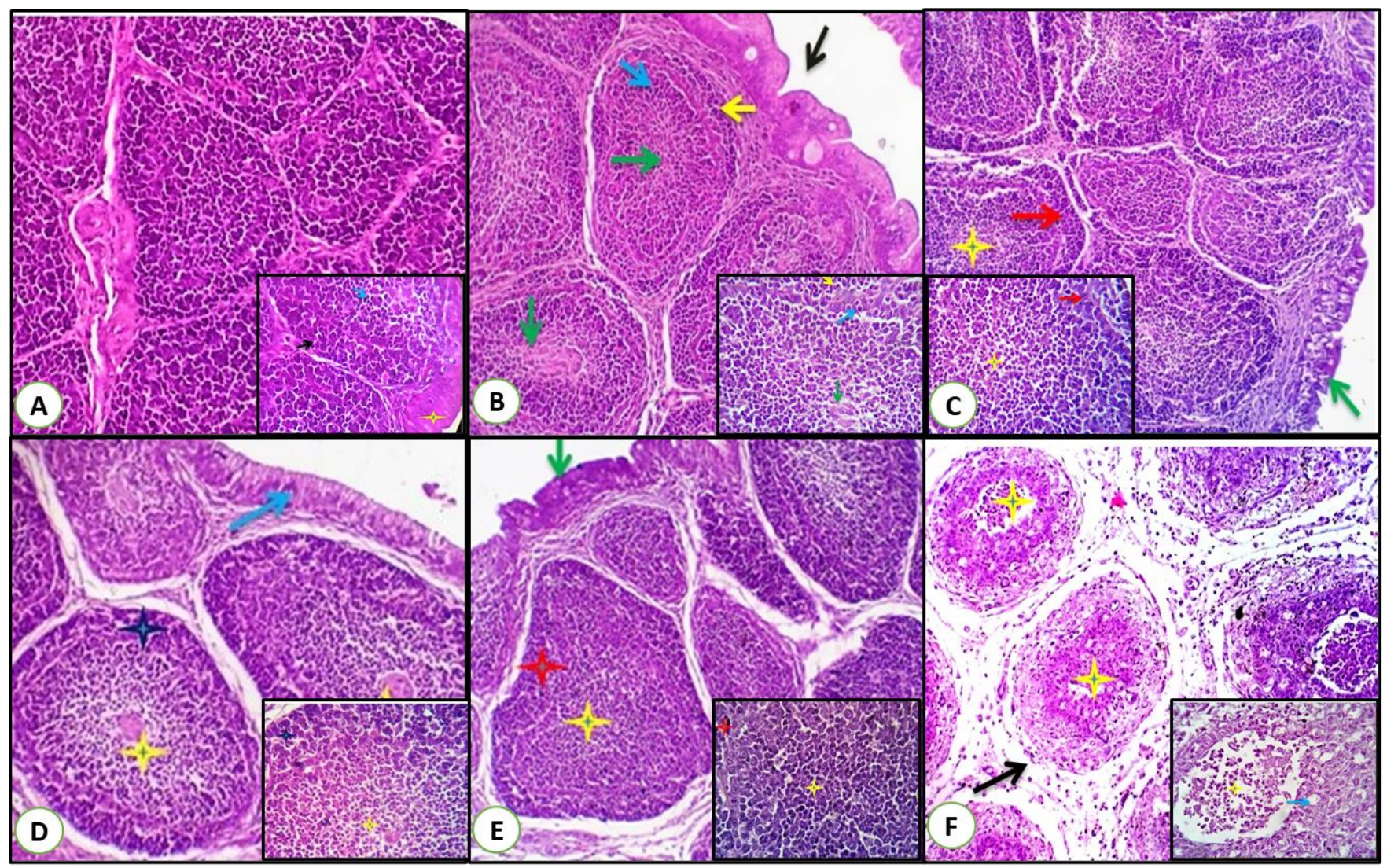

Figure 4. Bursa histopathology in different groups at 28 day-old. A: normal bursal histology in the negative control group. B: Bursaplex vaccinated non challenged group showing mucosal folds clear margins of the follicles, a layer of undifferentiated epithelial cells occupied the periphery of the medulla (green arrows). Both cortical (blue and yellow arrows) and medullary cellular contents (green arrows) are moderately reactive with closely backed small and large lymphocytes. C: intermediate/intermediate plus vaccinated non challenged group showing large sized follicles with proliferation of the cortical (red arrows) and medullary cells (yellow stars), the medullary centers appear slightly pale and crowded by large proliferating B-cells (yellow stars). D: Bursaplex vaccinated challenged group showed healthy epithelial lining of the pica (blue arrow) and lymphoproliferative follicular tissue (yellow stars), highly activated cortical lymphocytes with deep basophilic nuclei, and scanty cytoplasm (dark blue stars). E: intermediate/intermediate plus vaccinated challenged group showing normal bursal folds (green arrows), multiple immune-reactive lymphoid follicles (red stars and yellow stars), and mild thickening of the interstitial connective tissue by fibroblastic proliferation (green star). F: challenge control group showing massive medullary necrosis, apoptosis, heterophilic infiltration with central aggregates of necrotic and apoptotic debris (yellow stars and black arrows), the cortical layer appeared completely necrotic with the complete lymphoid cell depletion (blue stars).

Table 2. Daily mortalities and protection percent in different vaccinated chickens against vvIBDV challenge

\begin{tabular}{|c|c|c|c|c|c|c|c|c|}
\hline \multirow[t]{2}{*}{ Challenge } & \multirow[t]{2}{*}{ Groups } & \multicolumn{6}{|c|}{$\begin{array}{c}\text { Daily Mortalities } \\
\text { (days post-challenge) }\end{array}$} & \multirow[t]{2}{*}{ Protection \% } \\
\hline & & 3 & 4 & 5 & Live & Dead & Total & \\
\hline \multirow{3}{*}{ No } & Negative control & - & - & - & 20 & 0 & 20 & 100 \\
\hline & Bursaplex $^{1}$ & 0 & 0 & 0 & 20 & 0 & 20 & 100 \\
\hline & Interm. /Interm. Plus ${ }^{2}$ & 0 & 0 & 0 & 20 & 0 & 20 & 100 \\
\hline \multirow{3}{*}{ Yes } & Bursaplex- $\mathrm{CH}^{1}$ & 0 & 0 & 0 & 20 & 0 & 20 & 100 \\
\hline & Interm. /Interm. Plus-CH ${ }^{2}$ & 0 & 0 & 0 & 20 & 0 & 20 & 100 \\
\hline & Challenge control & 0 & 5 & 3 & 12 & 8 & 20 & 40 \\
\hline
\end{tabular}

\footnotetext{
${ }^{1}$ Vaccination schedule: $1^{\text {st }}$ day: Bursaplex ${ }^{2}$ Vaccination schedule: $9^{\text {th }}:$ intermediate IBD vaccine- $14^{\text {th }}$ day: intermediate plus IBD vaccine
} 
Table 3. Body weights in different experimental groups at 21 and 28 day-old chickens

\begin{tabular}{|c|c|c|c|c|c|c|c|}
\hline \multirow{2}{*}{ Age } & & \multirow{2}{*}{ Control Neg } & \multicolumn{2}{|c|}{ Non challenged } & \multicolumn{2}{|c|}{ Challenged } & \multirow{2}{*}{$\begin{array}{l}\text { Challenge } \\
\text { control }\end{array}$} \\
\hline & & & Bursaplex & Interm./Interm. plus & Bursaplex- CH & Interm./Interm. Plus-CH & \\
\hline \multirow{2}{*}{$\begin{array}{l}21 \\
\text { days }\end{array}$} & Mean & 128.86 & 131.89 & 126.87 & 124.35 & 123.12 & 122.68 \\
\hline & $\mathrm{SD}$ & 9.07 & 19.17 & 13.60 & 8.40 & 13.03 & 12.85 \\
\hline \multirow{2}{*}{$\begin{array}{l}28 \\
\text { days }\end{array}$} & Mean & 175.93 & 157.94 & 158.06 & 157.30 & 162.84 & 144.84 \\
\hline & SD & 35.61 & 15.37 & 8.10 & 15.72 & 10.77 & 5.88 \\
\hline
\end{tabular}

Table 4. Very virulent and vaccinal IBDV shedding detection at 28 day-old in vaccinated and vaccinated-challenged groups

\begin{tabular}{|c|c|c|c|c|}
\hline \multirow{2}{*}{ Group } & \multirow{2}{*}{ Sample } & \multicolumn{3}{|c|}{ IBDV virus detection by RT-PCR } \\
\hline & & Very virulent IBDV & Vaccinal IBDV & Result \\
\hline Bursaplex & \multirow{6}{*}{ 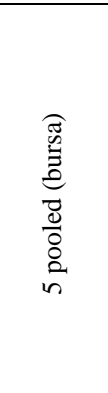 } & - & 28,6 & $\begin{array}{c}\text { vvIBDV: NEG } \\
\text { vacc.IBDV: POS }\end{array}$ \\
\hline Interm./Interm. plus & & - & 24,3 & $\begin{array}{l}\text { vvIBDV: NEG } \\
\text { vacc.IBDV: } \underline{P O S}\end{array}$ \\
\hline Bursaplex- $\mathrm{CH}$ & & - & 30,8 & $\begin{array}{c}\text { vvIBDV: NEG } \\
\text { vacc.IBDV: POS }\end{array}$ \\
\hline Interm./Interm. Plus-CH & & 24,0 & - & $\begin{array}{l}\text { vvIBDV: } \text { POS } \\
\text { vacc.IBDV: NEG }\end{array}$ \\
\hline Challenge Control & & 25,6 & - & $\begin{array}{l}\text { vvIBDV: } \text { POS } \\
\text { vacc.IBDV: NEG }\end{array}$ \\
\hline Negative control & & - & - & IBDV: NEG \\
\hline
\end{tabular}

\section{DISCUSSION}

In this study 2 vaccination schedules against vvIBDV were compared. Two live attenuated intermediate and intermediate plus vaccines at 9 and $14^{\text {th }}$ day-old, respectively versus an immune-complex vaccine (Bursaplex) at day-old. The performance, bursal gross lesions, antibody immune response, and bursal histopathology were evaluated in vaccinated non challenged and vaccinated challenged birds. All vaccinated groups were protected against the vvIBDV challenge compared to $40 \%$ mortality in the challenge control group. Though the challenge control showed lower body weight, however, these differences were not statistically significant.

Both the immune-complex and live attenuated IBD vaccine groups showed higher BB ratios compared to the negative control group. However, on the 28th day of age, the $\mathrm{BB}$ ratio in the immune-complex vaccinated challenged group was significantly lower than the live attenuated group. Immune-complex IBDV vaccines have shown lower BB ratios especially when administered via in-ovo vaccination compared to live vaccine (Le Gros et al., 2009; Roh et al., 2016). Though intermediate plus vaccines contain more pathogenic strains (Sedeik et al., 2019), however, the BB ratios did not significantly differ from those of the immune-complex vaccine that might be attributed to the use of 2 doses of intermediate vaccine on the $9^{\text {th }}$ day (Roh et al., 2016), and the intermediate plus vaccine at $14^{\text {th }}$ day allowing for better bursal recovery than using intermediate plus vaccine alone (Aihara et al., 2015; Lupini et al., 2020).

Serologically, the ELISA antibody titers follow up in vaccinated non challenged groups indicated that Bursaplex vaccinated groups antibody titers were significantly higher except at $28^{\text {th }}$ day of age, where the live attenuated vaccine was significantly higher. Similar results were previously reported (Zorman Rojs et al., 2011), where using an ELISA kit utilizing a bursa-derived antigen (e.g. Proflok plus IBD Ab kit, Synbiotics). After the challenge, the intermediate/intermediate plus vaccinated challenged group has significantly higher antibody titers at $21^{\text {st }}$ and $35^{\text {th }}$ days of age indicating more challenge virus replication compared to the immune-complex group (Abaza et al., 2020). These results were confirmed by the challenge virus detection and quantification on the $28^{\text {th }}$ day where the vvIBDV was detected with high cycle thresholds (ct) value using the real-time RT-PCR indicating high shedding titers of the challenge virus (Techera et al., 2019). Conversely, a recent study showed that both immune-complex and live attenuated IBD vaccines did not induce sterile immunity as the challenge virus was detected in both groups (Ivanet al., 2005; Prandiniet al., 2016).

The immune-complex vaccinated challenged group developed milder bursal histopathology but the difference to the intermediate/intermediate plus vaccination regime was not significant. Previously, IBD live-vaccinated birds 
displayed comparable histopathology to the challenge control group (Prandini et al., 2016; Kurukulasuriya et al., 2017), however, the alleviated bursal damage in the intermediate/intermediate plus vaccinated group may be attributed to the adjacent dosing regimen followed in the current study (i.e. $9^{\text {th }}$ and $14^{\text {th }}$ day of age). It is worthy to note that the current study was conducted in specific pathogen free chickens in the absence of maternally derived antibodies. Previous studies have shown that the immunocomplex vaccine showed poor immune response with even negative ELISA titers at 3 weeks of age due to the remaining neutralization antibody activity of the vaccine (Bose et al., 2016; Sedeik et al., 2019).

In conclusion, the use of either immune-complex vaccine at day-old or early vaccination with intermediate and intermediate plus live attenuated IBD vaccines induced protective antibody titers and both programs were clinically protective against an early vvIBDV challenge. However, the immune-complex vaccine induced sterile immunity as the challenge virus was not detected on the $28^{\text {th }}$ day of age. Similar programs testing in commercial broilers in the presence of maternal derived IBD antibodies to simulate field conditions are required.

\section{REFERENCES}

Abaza MA, Elboraay EM, Saad AE and Zayan KA (2020). Assessment of the role of intracloacal inoculation of live infectious bursal disease vaccine in breaking through maternally derived antibodies. Avian Pathology, 1-8. DOI: https://www.doi.org/10.1080/03079457.2020.1796925

Aihara N, Horiuchi N, Hikichi N, Ochiai M, Hosoda Y, Ishikawa Y, Shimazaki Y and Oishi K (2015). Immunoreactivity and morphological changes of bursal follicles in chickens infected with vaccine or wild-type strains of the infectious bursal disease virus. Journal of Veterinary Medical Science. 77 (8): $\quad 913-918 . \quad$ DOI: https://www.doi.org/10.1292/jvms.14-0599

Alkie TN and Rautenschlein S (2016). Infectious bursal disease virus in poultry: Current status and future prospects. Veterinary Medicine: Research and Reports, 7: 9-18. DOI: https://www.doi.org/10.2147/VMRR.S68905

Bose RK, Hossain KM, Sil BK, Taimur M, Pugliese C and Franci O (2016). Comparative seroevaluation of live and killed gumboro vaccine in broilers. Italian Journal of Animal Science. 2 (2): 157-162. DOI: https://www.doi.org/10.4081/ijas.2003.157

Camilotti E, Moraes L, Furian T, Borges K, Moraes H and Salle C (2016). Infectious bursal disease: Pathogenicity and immunogenicity of vaccines. Brazilian Journal of Poultry Science, $\quad 18$ : 303-308. DOI: https://www.doi.org/10.1590/1806-9061-2015-0148

Delmas B, Attoui H, Ghosh S, Malik YS, Mundt E, Vakharia VN and Ictv Report C (2019). Ictv virus taxonomy profile:
Birnaviridae. Journal of General Virology, 100 (1): 5-6. DOI: https://www.doi.org/10.1099/jgv.0.001185

Dey S, Pathak DC, Ramamurthy N, Maity HK and Chellappa MM (2019). Infectious bursal disease virus in chickens: Prevalence, impact, and management strategies. Veterinary Medicine: Research and Reports, 10: 85-97. DOI: https://www.doi.org/10.2147/VMRR.S185159

Eterradossi N and Saif YM (2016). Infectious bursal disease (gumboro disease). In: Manual of diagnostic tests and vaccines for terrestrial animals. World Organisation for Animal Health, Chapter 3.3.12.

Eterradossi N and Saif YM (2020). Infectious bursal disease. In: Diseases of poultry. 14, Swayne DE, Boulianne M, Logue CM, McDougald LR, Nair V, Suarez DL, Wit Sd, Grimes T, Johnson D, Kromm M et al. Hoboken, NJ 07030, USA. John Wiley \& Sons, Inc, 257-283. https://www.doi.org/10.1002/9781119371199.ch7

Ewies SS, Ali A, Tamam SM and Madbouly HM (2017). Molecular characterization of Newcastle disease virus (genotype vii) from broiler chickens in Egypt. Beni-Suef University Journal of Basic and Applied Sciences, 6 (3): 232-237.

DOI: https://www.doi.org/10.1016/j.bjbas.2017.04.004

Ingrao F, Rauw F, Lambrecht B and Van den Berg T (2013). Infectious bursal disease: A complex host-pathogen interaction. Developmental \& Comparative Immunology, 41 (3): 429-438. DOI: https://www.doi.org/10.1016/j.dci.2013.03.017

Ivan J, Velhner M, Ursu K, German P, Mato T, Dren CN and Meszaros J (2005). Delayed vaccine virus replication in chickens vaccinated subcutaneously with an immune complex infectious bursal disease vaccine: Quantification of vaccine virus by real-time polymerase chain reaction. Canadian Journal of Veterinary Research, 69 (2): 135-142.

Kurukulasuriya S, Ahmed KA, Ojkic D, Gunawardana T, Goonewardene K, Gupta A, Chow-Lockerbie B, Popowich S, Willson P, Tikoo SK et al. (2017). Modified live infectious bursal disease virus (IBDV) vaccine delays infection of neonatal broiler chickens with variant IBDV compared to turkey herpesvirus (HVT)-IBDV vectored vaccine. Vaccine, 35 (6): 882-888. DOI: https://www.doi.org/10.1016/j.vaccine.2017.01.005

Le Gros FX, Dancer A, Giacomini C, Pizzoni L, Bublot M, Graziani M and Prandini F (2009). Field efficacy trial of a novel hvt-ibd vector vaccine for 1-day-old broilers.

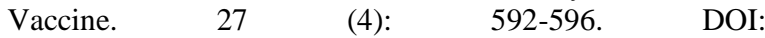
https://www.doi.org/10.1016/j.vaccine.2008.10.094

Lupini C, Quaglia G, Mescolini G, Russo E, Salaroli R, Forni M, Boldini S and Catelli E (2020). Alteration of immunological parameters in infectious bronchitis vaccinated-specific pathogen-free broilers after the use of different infectious bursal disease vaccines. Poultry Science, 99 (9): 4351-4359. DOI: https://www.doi.org/10.1016/j.psj.2020.05.054

Muller H, Mundt E, Eterradossi N and Islam MR (2012). Current status of vaccines against infectious bursal disease. Avian

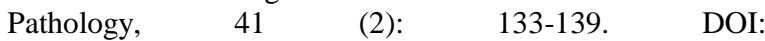
https://www.doi.org/10.1080/03079457.2012.661403

Perozo F, Villegas AP, Fernandez R, Cruz J and Pritchard N (2009). Efficacy of single dose recombinant herpesvirus of 
turkey infectious bursal disease virus (IBDV) vaccination against a variant IBDV strain. Avian Diseases, 53(4): 624628. DOI: https://www.doi.org/10.1637/868731009RESNOTE. 1

Prandini F, Simon B, Jung A, Poppel M, Lemiere S and Rautenschlein S (2016). Comparison of infectious bursal disease live vaccines and a HVT-IBD vector vaccine and their effects on the immune system of commercial layer pullets. Avian Pathology, 45 (1): 114-125. DOI: https://www.doi.org/10.1080/03079457.2015.1127891

Rautenschlein S, Yeh HY and Sharma JM (2003). Comparative immunopathogenesis of mild, intermediate, and virulent strains of classic infectious bursal disease virus. Avian Diseases, $47 \quad$ (1): $\quad 66-78 . \quad$ DOI: https://www.doi.org/10.1637/00052086(2003)047[0066:CIOMIA]2.0.CO;2

Roh JH, Kang M, Wei B, Yoon RH, Seo HS, Bahng JY, Kwon JT, Cha SY and Jang HK (2016). Efficacy of HVT-IBD vector vaccine compared to attenuated live vaccine using inovo vaccination against a Korean very virulent IBDV in commercial broiler chickens. Poultry Science, 95 (5): 10201024. DOI: https://www.doi.org/10.3382/ps/pew042

Schat KA, Martins NR, O'Connell PH and Piepenbrink MS (2011). Immune complex vaccines for chicken infectious anemia virus. Avian Diseases, 55 (1): 90-96. DOI: https://www.doi.org/10.1637/9347-032910-ResNote.1

Sedeik ME, El-Shall NA, Awad AM, Abd El-Hack ME, Alowaimer AN and Swelum AA (2019). Comparative evaluation of HVT-IBD vector, immune complex, and live IBD vaccines against vvIBDV in commercial broiler chickens with high maternally derived antibodies. Animals (Basel), $\quad 9 \quad$ (3). https://www.doi.org/10.3390/ani9030072

Sharma JM, Kim IJ, Rautenschlein S and Yeh HY (2000). Infectious bursal disease virus of chickens: Pathogenesis and immunosuppression. Developmental \& Comparative Immunology, $24 \quad(2-3): \quad 223-235$. DOI: https://www.doi.org/10.1016/s0145-305x(99)00074-9

Shehata AA, Sedeik ME, Elbestawy AR, Zain El-Abideen MA, Ibrahim HH, Kilany WH and Ali A (2019). Co-infections, genetic, and antigenic relatedness of avian influenza h5n8 and h5n1 viruses in domestic and wild birds in Egypt. Poultry Science, 98 (6): 2371-2379. DOI: https://www.doi.org/10.3382/ps/pez011

Sivanandan V and Maheswaran SK (1980). Immune profile of infectious bursal disease: I. Effect of infectious bursal disease virus on peripheral blood $t$ and $b$ lymphocytes of chickens. Avian Diseases, DOI: 24 (3): 715-725.

Stoute ST, Jackwood DJ, Sommer-Wagner SE, Cooper GL, Anderson ML, Woolcock PR, Bickford AA, Senties-Cue CG and Charlton BR (2009). The diagnosis of very virulent infectious bursal disease in California pullets. Avian Diseases, $\quad 53 \quad$ (2): $321-326 . \quad$ DOI: https://www.doi.org/10.1637/8684-030909-Case.1

Suvarna K, Layton C and Bancroft J (2018). Bancroft's theory and practice of histological techniques.8th, London, United Kingdom. Churchill Livingstone Elsevier.

Techera C, Tomas G, Panzera Y, Banda A, Perbolianachis P, Perez R and Marandino A (2019). Development of real-time PCR assays for single and simultaneous detection of infectious bursal disease virus and chicken anemia virus. Molecular and Cellular Probes, 43: 58-63. DOI: https://www.doi.org/10.1016/j.mcp.2018.11.004

Zorman Rojs O, Krapez U, Slavec B, Jursic-Cizerl R and Poljanec T (2011). Field efficacy of different vaccines against infectious bursal disease in broiler flocks. Acta Veterinaria Hungarica, 59 (3): 385-398. DOI: https://www.doi.org/10.1556/AVet.2011.016 